\title{
Mycorrhizal Colonization Status and Rhizosphere Soil Properties of BCSIR Reserve Forest Rajshahi, Bangladesh
}

\author{
M. HALDER ${ }^{1 *}$, A. K. DEY ${ }^{1}$, A. K. M. S. ALAM ${ }^{1}$, A. N. CHOWDHURY ${ }^{1}$, M. MONDAL ${ }^{2}$, \\ J. C. JOARDAR ${ }^{3}$, MD. S. AMIN ${ }^{3}$, D. K. ROY ${ }^{1}$ and M. H. KOBIR ${ }^{3}$ \\ 'Bangladesh Council of Scientific and Industrial Research (BCSIR), \\ Rajshahi-6206, Rajshahi, Bangladesh. \\ ${ }^{2}$ Govt. B. L. College, Khulna, Bangladesh. \\ ${ }^{3}$ Soil Science Discipline, Khulna University, Bangladesh. \\ http://dx.doi.org/10.12944/CWE.11.3.05
}

(Received: August 03, 2016; Accepted: September 16, 2016)

\begin{abstract}
The present investigation has been conducted to assess the AMF (Arbusculr Mycorrhiza Fungi) colonization status along with rhizosphere soil properties of dominant plants and grass species in Rajshahi BCSIR forest of Bangladesh. Roots of six dominant plants (Psidium guajava, Swietenia mahagoni, Artocarpus heterophyllus, Manihot esculenta, Acalypha indica, Fragaria ananassa) and two grass species (Digitaria sanguinalis, Cynodon dactylon) were collected and rhizosphere soil samples were collected from rhizosphere zone. Mycorrhizal colonization percentages and edaphic factors (Soil pH, EC, N, P, Moisture and Soil Temperature) were documented. Highest colonization was obtained in Manihot esculenta $(85 \pm 5 \%)$ followed by Swietenia mahagoni $(78 \pm 10.36 \%)$ and lowest was observed in Acalypha indica (2 $\pm 1.9 \%)$. Mycorrhizal structure as arbuscles, vesicles were present in Psidium guajava, Swietenia mahagoni, Manihot esculenta among the studied species. Research findings indicate that plants species of Rajshahi BCSIR forest is mycorrhizal but not well established as well as mycorrhizal infection is irregularly correlated with edaphic factors.
\end{abstract}

Keywords: Mycorrhiza; Colonization; Soil properties; Plants; Grass; Species.

\section{INTRODUCTION}

Bangladesh faces lots of environmental as well as economic constraints, so it is urgent to formulate least expensive and simple methodologies for immediate benefit. Different technologically simple methods are available but Mycorrhizal technology can be one of the most impressive alternatives to improve environmental quality, forest products and farm profitability in different production systems in Bangladesh'1.

Mycorrhizal fungi increase absorption of water and transportation of mineral nutrients from the soil solution to the mycorrhiza colonize plants species and fungi obtain carbohydrates produced by the plant species in photosynthesis. Mycorrhiza enhances plant growth and vitality ${ }^{2}$ and protects plants against absorption of toxic compounds from soil ${ }^{3}$. This fungi colonization is mainly important for plant hosts that grow in nutrient-poor soil conditions ${ }^{4}$. They can improve plant growth by up taking $P$ and help plants to absorb $\mathrm{N}, \mathrm{K}, \mathrm{Ca}, \mathrm{S}, \mathrm{Cu}$, and $\mathrm{Zn}^{5}$; water absorption ${ }^{6}$; produce glomalin ${ }^{7}$; heavy metal sequestration ${ }^{8}$; enhance the salt tolerance ${ }^{9}$; decrease disease incidence ${ }^{10}$. Mycorrhizal fungi can be affected by soil solution $\mathrm{pH}$, elevated soil nitrogen and drought, low availability of nutrients, high concentration of available trace metals. Root growth and mycorrhiza are also negatively influenced by poor soil aeration due to the soil texture ${ }^{4}$. So, it is important to encourage AMF relationship with 
plant root and utilization of Biofertilizer. Although in Bangladesh, there are different types of forest tree species in Rajshahi BCSIR, very little work about the status of Arbuscular Mycorrhizal Fungi (AMF) in forest tree species has been done in our country ${ }^{11}$. Some works on Mycorrhizal diversity and effects in different forest species (e.g vegetables, woody plants, spices plants, ornamental plants etc.) in different region of Bangladesh has also been investigated ${ }^{12-15}$. Halder et $a^{16}$ studied degree of vertical colonization and relationship with soil properties as well as seasonal variation of AMF colonization in Chittagong BCSIR reserve forest ${ }^{17}$. But no works has been performed in Rajshahi BCSIR reserve forest. The objectives of the present study were to investigate the occurrence and colonization of AM Fungi in the roots and determine rhizosphere soil properties of different forest tree species in Rajshahi BCSIR reserve forest.

\section{MATERIALS AND METHODS}

\section{Study site}

Rajshahi BCSIR laboratory is a government research organization under the Ministry of Science and Technology, People's Republic of Bangladesh. BCSIR forest is the reserve forest as specialized for research on local available plants species. It is situated at $24^{\circ} 21^{\prime} 58.4^{\prime \prime} \mathrm{N} 88^{\circ} 39^{\prime} 04.2^{\prime \prime} \mathrm{E}$ in the north-western part of Bangladesh, with an area of approximately 98 acres.

\section{Sample collection, processing and analysis}

Selected plant's roots and rhizosphere soil samples were collected during March-April, 2016 in summer. Recorded precipitation and temperature was $40-42^{\circ} \mathrm{C}$ and $0.02-3.31 \mathrm{~mm}$ respectively during the period of sample collection. Roots and soil samples were collected from selected dominant plants species (Table 1) of Rajshahi BCSIR reserve forest at $0-15 \mathrm{~cm}$ depth. All the samples were replicated three times.

Gravels and unwanted particles were removed by sieving the soil with a $2 \mathrm{~mm}$ sieve. Roots were washed well and chopped into $1 \mathrm{~cm}$ pieces. Clean root samples were stained by following the procedures of Phillips and Hayman [18]. Root samples were heated in $10 \% \mathrm{KOH}$ solution for $20 \mathrm{~min}$ at $90^{\circ} \mathrm{C}$ and deeply pigmented roots were treated in $3 \% \mathrm{H}_{2} \mathrm{O}_{2}$ at room temperature for 5 minutes. Roots treated with $3 \% \mathrm{H}_{2} \mathrm{O}_{2}$ were acidified in $1 \% \mathrm{HCl}$ solution for overnight and stained with $0.05 \%$ acidic aniline blue solution (1:1:1=Water: Glycerol: Lactic Acid) and heated at $80-85^{\circ} \mathrm{C}$ for 20 minutes. Stained roots were destained in $50 \%$ glycerol solution to remove excess stains and preserved for microscopic observation. The observed pictures were given in fig 1.

A total of 10 segments of each roots were mounted on the microscopic slides with $50 \%$ glycerol and smashed softly after placing a cover glass on the root pieces. Roots segments were observed by a compound microscope at $(20 \times 10)$ magnification. Percent root colonization was calculated by following the method describe by McGonigle et a ${ }^{19}$. Presence of mycelium was regarded as the AM positive and total mycelial colonization was treated as the percentage root colonization. Percent root

Table 1: List of plant and grass species of BCSIR reserve forest of Rajshahi, Bangladesh

\begin{tabular}{llll}
\hline $\begin{array}{lll}\text { SI } \\
\text { No. }\end{array}$ & Scientific Name & Family Name & Habit \\
\hline 1 & Psidium guajava L. & Myrtaceae & Shrub \\
2 & Swietenia mahagoni (L.) Jacq. & Meliaceae & Tree \\
3 & Artocarpus heterophyllus Lam. & Urticaceae & Tree \\
4 & Manihot esculenta Crantz & Euphorbiaceae & Herb \\
5 & Acalypha indica L. & Euphorbiaceae & Herb \\
6 & Fragaria Ananassa Duchesne & Rosaceae & Herb \\
7 & Digitaria sanguinalis (L.) Scop. & Poaceae & Herb \\
8 & Cynodon dactylon (L) Pers & Poaceae & Herb \\
\hline
\end{tabular}


colonization was calculated by using the following formula

Percent colonization $(\%)=\frac{\text { Number of AM positive segments }}{\text { Total number of segments observed }} \mathrm{X} 100$

\section{Soil analysis}

Soil properties of the selected dominant plant specie's rhizosphere zone were determined as described the standard protocol of Halder et $a^{16}$. From each soil sample, three replicated soil samples were studied for analyzing the soil properties. Soil pH (soil: water $=1: 2.5$ ) and EC (soil: water $=1: 2.5$ ) were determined. Available $\mathrm{P}$, total $\mathrm{N}$, soil temperature and soil moisture content were determined and analyzed.

\section{Statistical analyses}

Mean value $(n=3)$ and standard deviations were determined by the MS Excel 2007 software. ANOVA, among fungi colonization percentage of studied plants and grass species, was performed
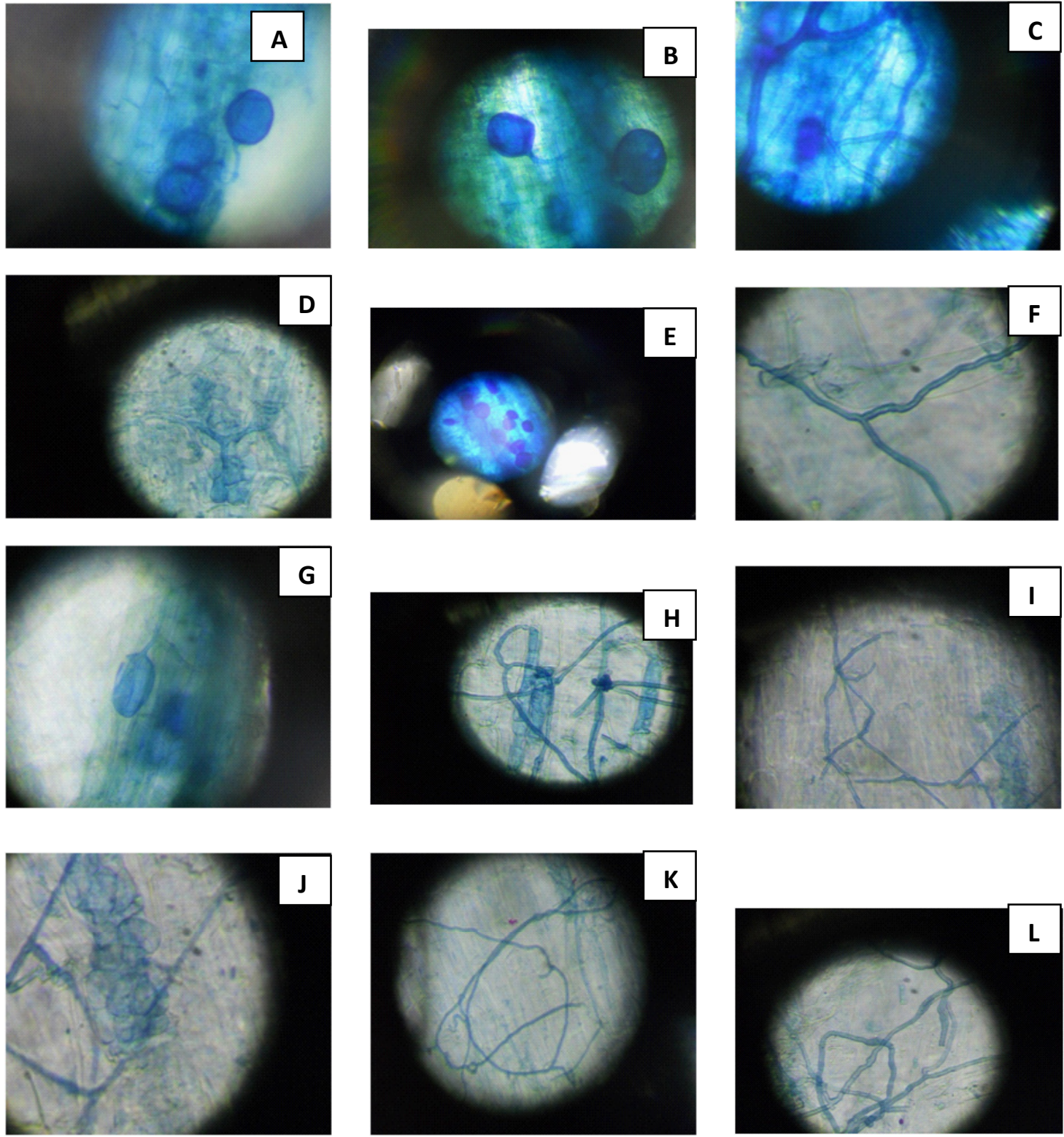

Fig. 1: Mycorrhizal Mycellium (C, F, H, I, J, K, L), Arbuscle (D, J), Vesicle (A, B, E, G) in the root cortex of studied plant (Artocarpus heterophyllus) in BCSIR reserve forest 
at $0.05 \%$ levels of significance by using SAS 6.0 . Bivariate Pearson's correlation was applied to determine the relationship between soil properties and fungi colonization percentage of the host plant species by using SPSS 16.0.

\section{RESULTS AND DISCUSSION}

\section{Mycorrhizal colonization status}

High mycorrhizal infection was recorded in Manihot esculenta ( $85 \pm 4 \%$ ) followed by Swietenia mahagoni $(78 \pm 10.36 \%)$ and lowest colonization was investigated in Acalypha indica ( $2 \pm 2 \%$ ). But between two grass species as Cynodon dactylon
$(6 \pm 2.24 \%)$ and Digitaria sanguinalis (40 $\pm 21.21 \%)$ one was very little percentage colonized by AMF.

Strawberry plants $(10 \pm 1 \%)$ was also little percentage colonized but woody plants species Artocarpus hterophyllus (55 $\pm 19.6 \%$ ) was highly mycorrhiza infected. All the studied plants species infection rates were presented in fig. 2.

Percentage of arbuscle and vesicle were differed widely within studied plants species (Table 2). Within the studied plants species, mycorrhizal structure as arbuscles, vesicle infection were absent in studied $60 \%$ plants root cortex and only $40 \%$

Table 2: Status of Arbuscle and Vesicle percentage in studied plants and grass specie's root of BCSIR reserve forest at Rajshahi in Bangladesh

\begin{tabular}{llll}
\hline $\begin{array}{l}\text { SI. } \\
\text { No }\end{array}$ & Plants Name & $\begin{array}{l}\text { Presence of } \\
\text { Arbuscle (\%) }\end{array}$ & $\begin{array}{l}\text { Presence of } \\
\text { Vesicle (\%) }\end{array}$ \\
\hline 1 & Psidium guajava & 16.66 & 54 \\
2 & Swietenia mahagoni & 16.66 & 73 \\
3 & Artocarpus heterophyllus & 0 & 0 \\
4 & Manihot esculenta & 25 & 25 \\
5 & Acalypha indica & 0 & 0 \\
6 & Fragaria ananassa & 0 & 0 \\
7 & Digitaria sanguinalis & 0 & 0 \\
8 & Cynodon dactylon & 0 & 0 \\
\hline
\end{tabular}

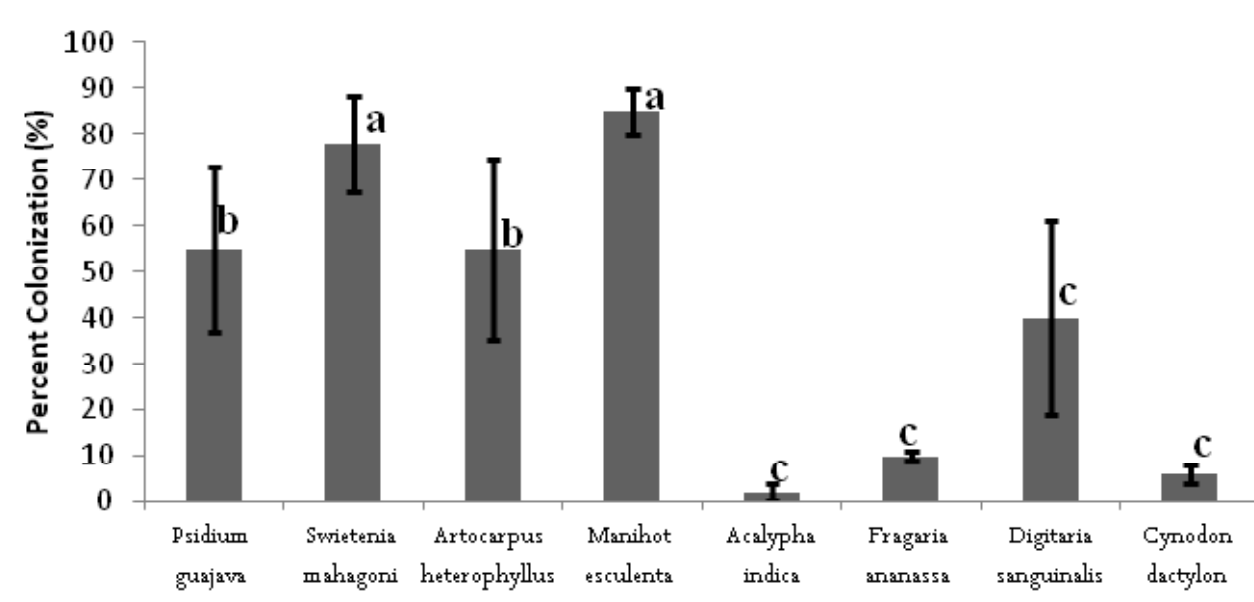

Name of studied plants

Fig. 2: AMF colonization status of dominant plant species in Rajshahi BCSIR reserve forest, Different letters indicate significant difference at $0.05 \%$ level but same letters indicate there is no significant difference. Error Bar Indicates Standard Deviation (SD), $n=3$ 
plants species was colonized with arbuscle and vesicle. Highest percentage (25\%) of arbuscle was observed in Manihot esculenta followed by Psidium guajava (16.66\%) and Swietenia mahagoni (16.66\%) but another all studied plants species were free from any kinds of arbusle structure in root cortex. Ratio of vesicles in compare to arbucle structure in plant root of studied plants was higher. In the root of Swietenia mahagoni (73\%) was highly vesicle present followed by Psidium guajava (54\%). Only $25 \%$ vesicle same as arbuscle was determined in Manihot esculenta plant species. Apart from the three selected studied plants species as Swietenia mahagoni, Psidium
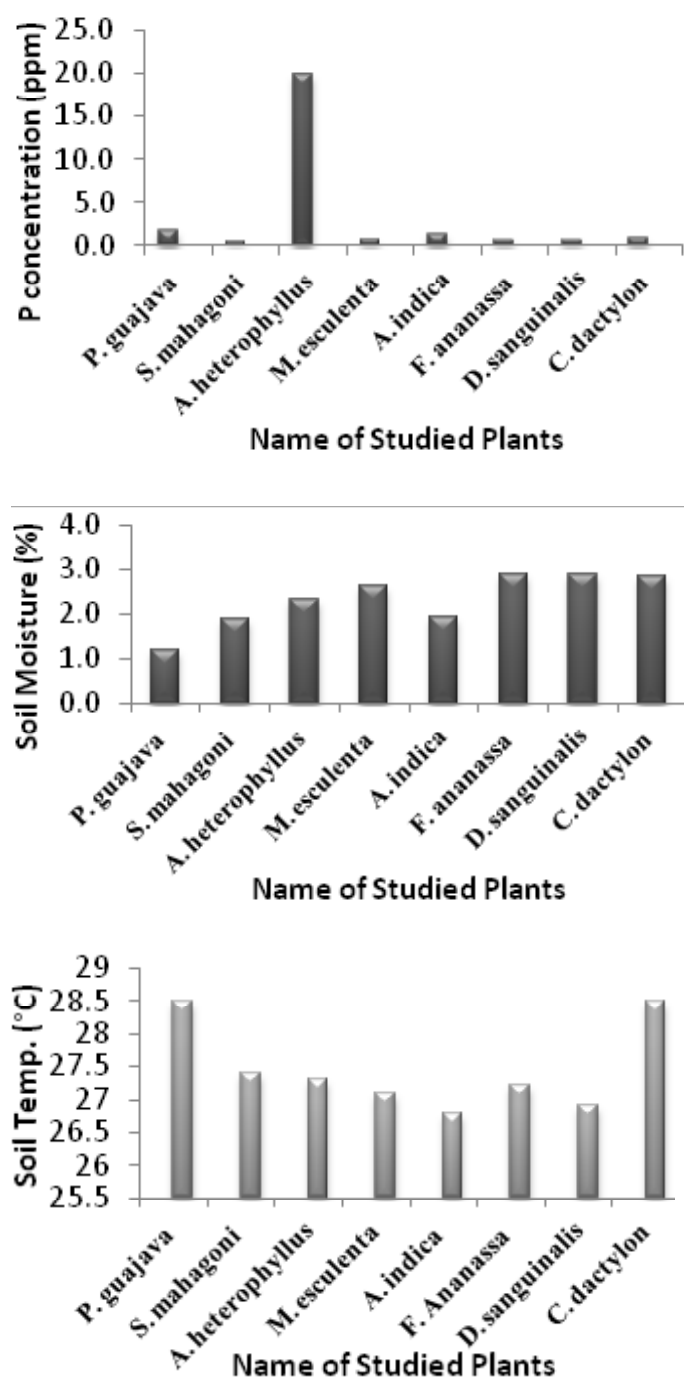

guajava, Manihot esculenta other studied species were totally absent from vesicle structure.

\section{Rhizosphere soil properties and AMF infection}

The rhizosphere soil properties (Soil $\mathrm{pH}$, EC, Available P, Total N, Soil Temperature, Soil Moisture) of some dominant plant along grass species of Rajshahi BCSIR reserve forest were presented below in fig. 3 .

The range of $\mathrm{pH}$ of rhizosphere soil of studied reserve forest was 5.8 to 7.8 as acidic to slightly alkaline soil. In Fragaria ananassa and
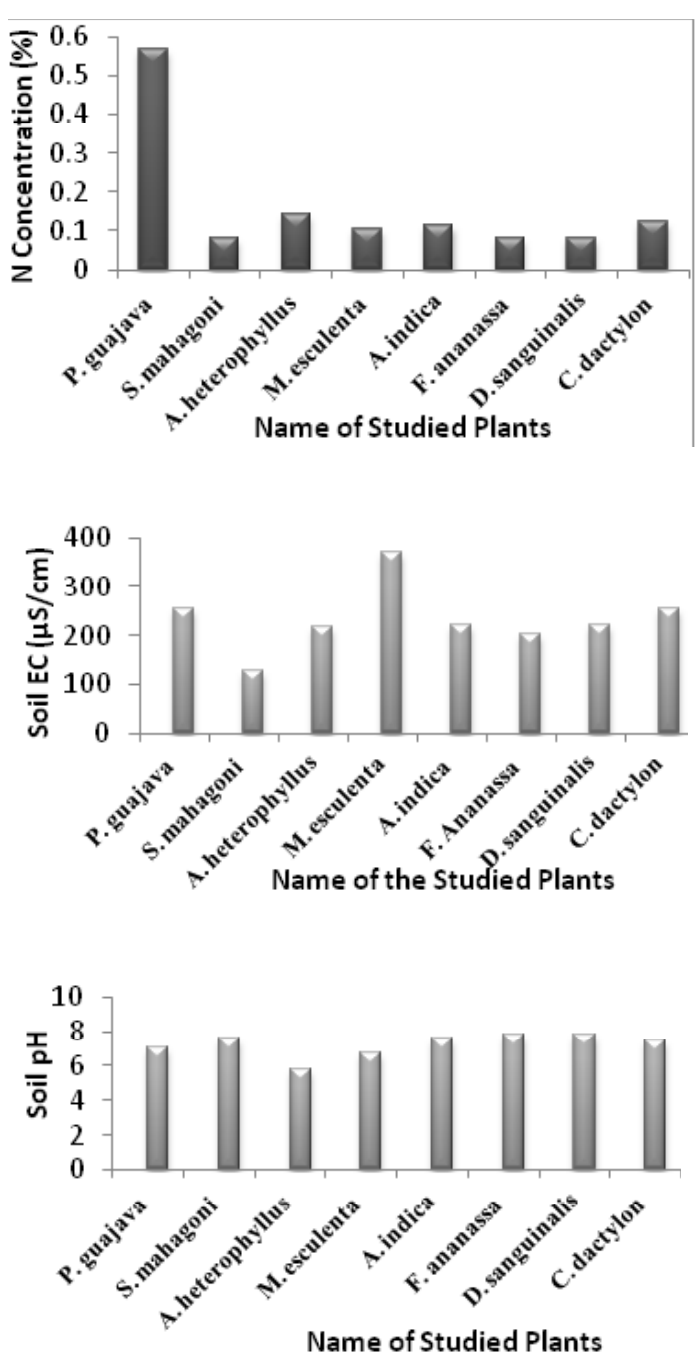

Fig. 3: Edaphic factors in rhizosphere zone of studied plants and grass species in Rajshahi BCSIR reserve forest 
Table 3: Pearson's correlation between AMF colonization and edaphic factors in study area

\begin{tabular}{|c|c|c|c|c|c|c|c|}
\hline & Colonization & $\mathbf{P}$ & $\mathbf{N}$ & Moisture & $\mathrm{pH}$ & EC & Temp. \\
\hline Colonization & 1 & & & & & & \\
\hline$P$ & .153 & 1 & & & & & \\
\hline $\mathrm{N}$ & .150 & .005 & 1 & & & & \\
\hline Moisture & -.275 & -.057 & $-.749^{*}$ & 1 & & & \\
\hline $\mathrm{pH}$ & -.468 & $-.850^{* *}$ & -.178 & .172 & 1 & & \\
\hline EC & .184 & -.085 & .153 & .174 & -.348 & 1 & \\
\hline Temp. & -.051 & -.066 & .657 & -.328 & -.052 & .074 & 1 \\
\hline
\end{tabular}

${ }^{*}$ and ${ }^{* *}$ indicates correlation significant at 0.05 and 0.01 levels, respectively

Digitaria sanguinalis AMF colonization percentage were 10 and 40 but $\mathrm{pH}$ was 7.8 otherwise in Artocarpus heterophyllus colonization was $55 \%$ but $\mathrm{pH}$ was 5.8. Highest Mycorrhiza infection rate was observed in $\mathrm{pH}$ 6.7. From data it was prominent that most of the infection was favored in slightly lower $\mathrm{pH}$ range. Mycorrhiza was established but varied with $\mathrm{pH}$ and favored to lower $\mathrm{pH}$ range condition which opposed the work of Halder et $a^{16}$. P concentration was varied widely (19.94 ppm to $0.51 \mathrm{ppm}$ ) but most of the data varied within a narrow range as $1.7 \mathrm{ppm}$ to $0.51 \mathrm{ppm}$. Root of Manihot esculenta colonized highest percentage of Mycorrhiza but $P$ concentration in respective plant rhizosphere root zone soil was 0.7 ppm. Except the value of Artocarpus heterophyllus (Infection rate: 55\%, P concentration: 19.94 ppm), in most cases AMF colonization rate was reduced with increasing rate of $\mathrm{P}$ concentration which coincide with the other researcher ${ }^{20}$ but not significant (Table 3). Another parameter was soil temperature was not varied within a large extent range, documented range from 26.8 to $28.5^{\circ} \mathrm{C}$ but there was no visible effects of soil temperature on Mycorrhiza infection that might be due to narrow range of variation. The most one of the dominant factor to control Mycorrhiza colonization is Soil salinity ${ }^{21}$ but our study area was non saline and far from sea as well as higher position from sea level. So, there was no possibility of salt accumulation in soil and documented conductivity levels was lower as range from 369 to $128 \mu \mathrm{S} / \mathrm{cm}$ and varied randomly with AMF colonization and structure formation. Moisture is one of the key edaphic factor for controlling AMF infection and arbusclar structure formation. Soil moisture content has a positive effect on Mycorrhiza colonization in respect of mycellia infection and arbuscle formation in root cortex.
The soil moisture content was ranged from $1.2 \%$ (Psidium guajava) to $2.9 \%$ (Fragaria ananassa) but highest colonization (85\%) was obtained in $2.6 \%$ moisture level in rhizosphere soil of Manihot esculenta and differed randomly. The rhizosphere soil nitrogen percentage was differed with in a narrow range from $0.567 \%$ (Colonization rate $55 \%$ ) to $0.083 \%$ (Colonization rate: $78-10 \%$ ). In Manihot esculenta rhizosphere soil nitrogen concentration was $0.104 \%$ and obtained highest colonization rate as $85 \%$ but slightly deviation from this point of data colonization also decreased.

Table 3. Pearson's correlation between AMF colonization and edaphic factors *and ** indicates correlation significant at 0.05 and 0.01 levels, respectively

\section{CONCLUSION}

Our experimental research result reveals that growing plant species in Rajshahi BCSIR reserve forest was mycorrhizal but not highly colonizes in all growing species. Mycorrhizal structure likes as arbuscle, vesicles were presence in some species but in most of them this structures were not well established in root cortex of studied plants. Documented soil properties were irregularly varied with AMF colonization but relationship between them was not significant.

\section{ACKNOWLEDGEMENT}

Author acknowledges to Director of Rajshahi BCSIR Laboratories Dr. Md. Munsur Rahman and Md. Ruhul Amin (Scientific Officer), 
Debashis Talukder (Principle Scientific Officer) for his cordial help to conduct the research. Author also acknowledges Applied Zoology Research Division,
Microbiology Research Division, Drug and Toxin Research Division and Biotechnology laboratories of Rajshahi BCSIR.

\section{REFERENCES}

1. Mridha, M.A.U., and Xu, H.L., Nature Farming with Vesicular-Arbuscular Mycorrhizae in Bangladesh. Journal of Crop Production. 3: 303-312(2001)

2. Perez-Moreno, J., and Read, D.J., Mobilization and transfer of nutrients from litter to tree seedlings via the vegetative mycelium of ectomycorrhizal plants, New Phytologist. 145: 301-309(2000)

3. Bothe, H., Regvar, M., Turnau, K., Arbuscular mycorrhiza, heavy metal and salt tolerance. In: Sherameti I, Varma A (eds) Soil heavy metals. Springer, Heidelberg, pp 87-111. (2009)

4. Smith, S.E., and Read, D.J., Mycorrhizal Symbiosis. 3rd edition Academic Press, Amsterdam, Boston (2008)

5. Jiang, W., Gou, G., and Ding, Y., Influences of arbuscular mycorrhizal fungi on growth and mineral element absorption of chenglu hybrid bamboo seedlings. Pak. J. Bot., 2013; 45(1): 303- 310(2013)

6. Dhar, P.P., and Mridha, M.A., Status of biodiversity of arbuscular mycorrhizal fungi in different tree species growing in Betagi community forests, The Chittagong Univ. J. Sci. 27:13-19(2003)

7. Guo, H., He, X., and Li, Y., Spatial distribution of arbuscularmycorrhiza and glomalin in the rhizosphere of CaraganakorshinskiiKom. in the Otindag sandy land, China. Afric. J. Microbiol. Res. 6: 5745-5753(2012)

8. Tonin, C.P., Vandenkoornhuyse, E.J., Joner Straczek, J., and Leyval, C., Assessment of arbuscular mycorrhizal fungi diversity in the rhizosphere of Viola calaminaria and effect of these fungi on heavy metal uptake by clover. Mycorrhiza. 10: 161-168(2001)

9. Evelin, H., Kapoor, R., and Giri, B., Arbuscular mycorrhizal fungi in alleviation of salt stress: A review. Ann Bot. 104: 1263-80(2009)

10. Linderman, R.G., Managing rhizosphere microbes to enhance plant growth and health.
In: Proc. International Workshop on Life Science in Production and Food Consumption of Agricultural Products. Oct. 24-28, Tsukuba, Japan(1993)

11. Halder, M., Samina, A., Mahmud, A.S.M., Islam, F., Mullick, R., Joardar, J.C., Amin, M.S., Karim, R., Talukder, R., and Rahman, M.S., Prevalence of Arbuscular Mycorrhiza Fungi (AMF) Colonization in Medicinal Plant Root and Response of Prevalence with Some Selected Medicinal Plants Rhizosphere Soil Properties in BCSIR Forest, Chittagong, Bangladesh, Journal of Pure and Applied Microbiology. 9(1):131-140(2015a)

12. Halder, M., Dhar, P.P., Mujib, A.S.M., Khan, M.S., Joardar, J.C., and Akhter, S., Effect of Arbuscular Mycorrhiza Fungi Inoculation on Growth and Uptake of Mineral Nutrition in Ipomoea aquatica, Current World Environment. 10(1):67-75(2015b)

13. Mridha, M.A.U., and Dhar, P.P., Biodiversity of arbuscular mycorrhizal colonization and spore population in different agroforestry trees and crop species growing in Dinajpur, Bangladesh. Journal of Forestry Researc. 18(2): 91-96(2007)

14. Dhar, P.P., and Mridha, M.A.U., Biodiversity of arbuscular mycorrhizal fungi in different trees of madhupur forest, Bangladesh. Journal of Forestry Research. 17(3): 201-205(2006)

15. Dhar, P.P., Mridha, M.A.U., Bhuiyan, M.K.U., Mohiuddin, M., Status of arbuscular mycorrhizal fungi in gamari (Gmelina arborea Roxb.) growing in different parts of Bangladesh, The Chittagong University Journal of Science. 29(2):65-74(2005)

16. Halder, M., Samina, A., Nusrat, J.M., and Rahman, M.S., Vertical distribution of am colonization and relationship with soil properties in medicinal plants of BCSIR reserve forest Chittagong, Bangladesh, Bangladesh J. Bot. 45(1): 117-125(2016)

17. Halder, M., Akhter, S., Islam, S., and Karim, R., 
Seasonal variation of arbuscular mycorrhiza fungi colonization with some medicinal plant species of Chittagong BCSIR forest. Plant Science Today. 2(3): 87-92(2015c)

18. Phillips, J.M., and Hayman, D.S., Improved procedures for clearing roots for rapid assessment of infection. Trans. Brit. Mycol. Soc. 55: 158-161(1970)

19. McGonigle, T.P., Miller, M.H., Evans, D.G., Fairchild, G.L., and Swan, J.A., A new method, which gives an objective measure of colonization of roots by vesicular-arbuscular mycorrhizal fungi, New Phytologist. 115: 495-
501(1990)

20. Liu, L., Liao, H., Wang, X.R., and Yan, X.L., Regulation effect of soil $P$ availability on mycorrhizal infection in relation to root architecture and $\mathrm{P}$ efficiency of Glycine max. The Journal of Applied Ecology. 19(3):5648(2008)

21. Khaliel, A.S., Shine, K., and Vijaya, K.K., Salt tolerance and mycorrhization of Bacopamonneiri grown under sodium chloride saline conditions. African J. Microbiol. Res. 5(15): 2034-2040(2011). 